\title{
Effect of electric currents on antibacterial effect of chlorhexidine against Entrococcus faecalis biofilm: An in vitro study
}

\author{
Mohammad Froughreyhani ${ }^{1}$, Amin Salemmilani ${ }^{1}$, Aysan Mozafari $^{2}$, Mohammad Hosein-Soroush ${ }^{1}$
}

${ }^{1}$ Associate Professor. Department of Endodontics, Dental and Periodontal Research Center, Faculty of Dentistry, Tabriz University of Medical Sciences

${ }^{2}$ Post-graduate Student. Department of Endodontics, Dental and Periodontal Research Center, Faculty of Dentistry, Tabriz University of Medical Sciences

Correspondence:

Department of Endodontics

Dental and Periodontal Research Center

Faculty of Dentistry

Tabriz University of Medical Sciences

aisanmozaffary@gmail.com

Froughreyhani M, Salemmilani A, Mozafari A, Hosein-Soroush M. Effect of electric currents on antibacterial effect of chlorhexidine against Entrococcus faecalis biofilm: An in vitro study. J Clin Exp Dent. 2018;10(12):e1223-9.

Received: 18/10/2018 Accepted: 02/11/2018 http://www.medicinaoral.com/odo/volumenes/v10i12/jcedv10i12p1223.pdf

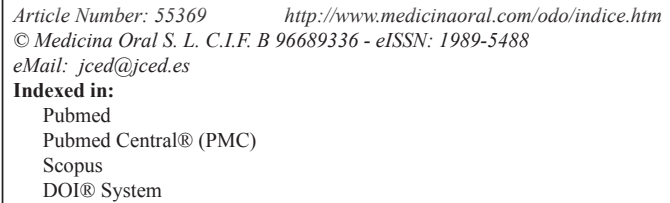

\begin{abstract}
Background: This in vitro study was mainly aimed to evaluate the effect of high-frequency alternating currents $(\mathrm{AC})$ applied by an electronic apex locator (EAL) on the antibacterial properties of chlorhexidine (CHX) on $E$. faecalis biofilm.

Material and Methods: The root canals of 120 extracted human single-rooted teeth were prepared using Gates-Glidden drills and hand K-files. After contaminating the root canals with E. faecalis, they were incubated for 60 days. Then, the teeth were randomly divided into six experimental groups $(\mathrm{n}=20)$. Group 1, 2\% CHX; group 2, normal saline (NS) with direct current (DC); group 3, normal saline (NS) with high-frequency alternating current (AC); group 4, 2\% CHX with DC; group 5, 2\% CHX with AC; group 6, control (normal saline). The samples were collected from the root canal walls of 16 teeth in each group and 1:10 serial dilutions were prepared and added to Muller-Hinton agar (MHA) plates and incubated at $37^{\circ} \mathrm{C}$ for $48 \mathrm{~h}$. The longitudinal sections of the other 4 teeth used to observe under a scanning electron microscope (SEM). A classic colony counting technique was used for counting the vital $E$. faecalis bacteria in MHA. Two-way ANOVA was used for statistical analysis of the data. The level of significance was set at $P<0.05$.

Results: The electric current significantly changed the colony-forming units $(\mathrm{CFU})$ values $(P<0.001)$. According to pair-wise comparisons, the highest CFU difference was observed between the AC group and the group without electric current $(P<0.001)$; furthermore, the difference between the DC group and the group without electric current was not significant $(P=0.823)$.

Conclusion: The highest bioelectric effect occurred with the use of high-frequency alternating electric current in the form of an apex locator with CHX as a canal irrigant.
\end{abstract}

Key words: Biofilm, Chlorhexidine, Direct current, Electric current, Enterococcus faecalis. 


\section{Introduction}

Eradication of microorganisms from the root canal system is required for a successful root canal treatment. Use of root canal irrigants along with mechanical instrumentation and intracanal medication as the standard protocol of endodontic treatment results in the elimination of the majority of microorganisms from the root canal system (1). However, despite all the efforts in this field, failures still occur due to bacterial resistence. E. faecalis is one of the most prevalent bacterial strains isolated from cases with failed endodontic treatment $(1,2)$. It has been found in $24-77 \%$ of root canals of teeth with recalcitrant periapical lesions $(3,4)$. In addition to adaptation with the environment and resistance to antibacterial agents, $E$. faecalis is able to attach to root canal walls and produce bacterial biofilms (4-6). Biofilms show greatly increased resistance to antibiotics and antimicrobial agents (7) so that biofilm bacteria are resistant to antibacterial agents up to 5000 times $(4,6)$.This resistance apears to be due to their physiologic properties, including altered growth and diffusion barrier of biofilm matrix $(8,9)$. Therefore, many studies have evaluated antibacterial effects on $E$. faecalis biofilms (10-12).

Different methods have been used to improve antimicrobial potency against the biofilm bacteria. The effect of low-intensity electric currents on destruction of bacterial biofilms was shown in $1992(3,7)$ and also, it has been shown that the antibacterial effect of antimicrobial agents increased synergistacally with low-intensity electerical currents, a phenomenone called "bioelectric effect" $(3,5,7)$. An increased antibacterial effect of tobramicyn due to the use of electrical currents against Pseudomonas aeruginosa has been shown in various biofilm systems $(3,6,13-17)$. In addition, improved antibacterial effects of gentamicin against Staphylococcus gordonii (17) and cycloheximide against Candida albicans (7) have been demonstrated.

Different studies have shown the electricidal effect of electric currents on various bacteria without any antimicrobial agents (18-21) and to differentiate this phenomenon from bioelectric effect, it has been called "electricidal effect" (21). Studies have mostly used direct electric currents. Caubet et al. (5) used alternating high-frequency currents in their study and showed its synergism with gentamicin and oxytetracyclin against $E$. coli biofilm. There have been no studies evaluating the effect of electric current synergism on the antibacterial properties of root canal irrigants. Chlorhexidine is one of the most common canal irrigants which unlike the others shows low toxicity, low irritation of periapical tissues, tolerable odor and taste and substantivity. Despite favorable antibacterial charactristics against planktonic bacteria (22), CHX does not affect biofilm bacteria. Furthermore, the antibacterial efficiency of CHX reduces in contact with intracanal organic materials and dentin $(23,24)$.
Therefore, this study was carried out to evaluate the effect of antibacterial direct electric currents or high-frequency alternating currents alone or in conjunction with CHX against $E$. faecalis biofilm.

\section{Material and Methods}

The study was approved by the Research and Ethics Committee of Tabriz University of Medical Sciences. A total of 120 (25) human single-rooted teeth extracted because of periodontal diseases were selected for this in vitro study. All the teeth had mature single straight roots, with no root caries, previous endodontic treatments or anomalies. After extraction, the teeth were stored in 3\% chloramine-T solution at $4^{\circ} \mathrm{C}$. An ultrasonic scaler was used to remove any calculus and remaining periodontal tissues from the root surfaces. Then the tooth crowns were eliminated with diamond disks (18) at the level of CEJ to achieve root lengths of $12 \mathrm{~mm}$. The working length was determined using a \#15 K-Flexofile (Dentsply Maillefer, Ballaigues, Switzerland), $1 \mathrm{~mm}$ away from the apical foramen. The root canals were prepared with \#4, \#3, \#2 and \#1 Gates-Glidden drills (Dentsply, Maillefer, Ballaigues, Switzerland) using the crowndown technique. For the preparation of apical thirds of the root canals, K-files (Maillefer, Dentsply) up to \#50 were used. Each root canal was irrigated with $3 \mathrm{~mL}$ of $5.25 \% \mathrm{NaOCl}$ (Taj Corp, Tehran, IRI) between each file size. Finally, $1 \mathrm{~mL}$ of $17 \%$ ethylenediaminetetraacetic acid (EDTA, Pulpdent Corp, Watertown, MA, USA) was used for $3 \mathrm{~min}$ to remove the smear layer. The teeth were sterilized in an autoclave at $121^{\circ} \mathrm{C}$ and 15 psi pressure for $20 \mathrm{~min}$. To confirm the sterility of the teeth, they were incubated for 24 hours at $37^{\circ} \mathrm{C}$ in brain-heart infusion broth (BHI, Merck, Darmstadt, Germany).

\section{-E. faecalis Biofilm Preparation}

The teeth were passed through the holes created on the plastic caps of sterile penicillin vials containing BHI broth so that the apical ends of the teeth were placed within BHI.

A standard suspension of E. faecalis (ATCC 29212, Reference Laboratories of Iran Research Center, Tehran, Iran) was prepared in the Bacteriology Laboratory of Tabriz Faculty of

Medicine. The microorganisms were incubated for 24 hours in solid brain-heart infusion (BHI, Merck, Darmstadt, Germany) at $37^{\circ} \mathrm{C}$ and a final concentration of $3 \times 108 \mathrm{cell} / \mathrm{mL}$ ( $1 \mathrm{McFarland}$ turbidity) was prepared. Then $5 \mathrm{~mL}$ of bacterial suspension was mixed with 5 $\mathrm{mL}$ of sterile BHI broth and inoculated within the canals with a sterile micropipette. This procedure continued every 48 hours up to 60 days by placement of a fresh bacterial culture (1 McFarland turbidity) into the canals. During this time, the teeth were incubated at $37^{\circ} \mathrm{C}(26)$. -Antibacterial Protocols

After 60 days, the teeth were randomly divided into six 
experimental groups $(\mathrm{n}=20)$. Group 1, 2\% CHX; group 2 , normal saline (NS) with direct current (DC); group 3 , normal saline (NS) with high-frequency alternating current (22); group 4, 2\% CHX with DC; group 5, 2\% CHX with AC; group 6, control (normal saline). In group 1, the root canals were irrigated with $1 \mathrm{~mL}$ of $2 \%$ CHX solution (F.G.M., Joinville, Brazil), which remained in the canals for $5 \mathrm{~min}$ and then the canals were irrigated with $3 \mathrm{~mL}$ of sterile normal saline solution. In group 2, the root canals were irrigated with $1 \mathrm{~mL}$ of normal saline solution, and K-file \#50 which served as a cathode was placed up to the working length (WL) and connected to an electrical device that generated $0.6 \mathrm{~mA} \mathrm{DC}$ (a current density of $6 \mathrm{~mA} / \mathrm{cm}^{2}$ ) and the other wire that served as an anode was placed in the PBS and DC was applied for $5 \mathrm{~min}$. Then the canals were irrigated with $3 \mathrm{~mL}$ of sterile normal saline solution. In group 3, the root canals were irrigated with $1 \mathrm{~mL}$ of normal saline solution; then one K-file \#50 was placed up to the WL and connected to Root-Zx (J. Morita Corp, Kyoto, Japan) electronic apex locator that generated $\mathrm{AC}$ and the lip clip was in- serted in the PBS and it was activated for $5 \mathrm{~min}$. Then the canals were irrigated with $3 \mathrm{~mL}$ of sterile normal saline solution. In group 4, after irrigation with $2 \% \mathrm{CHX}$, DC was applied for 5 min similar to that in group 2 . Then the root canals were irrigated with $3 \mathrm{~mL}$ of sterile normal saline solution. In group 5, after irrigation with 2\% CHX, Root-Zx (J. Morita Corp, Kyoto, Japan) electronic apex locator was activated for 5 min similar to that in group 3; then the root canals were irrigated with $3 \mathrm{~mL}$ of sterile normal saline solution. In all the experiments, the flow of the electric current was confirmed by placing an ammeter.

After antimicrobial protocols, 4 teeth from each group were placed in $2.5 \%$ glutaraldehyde for 7 days and longitudinal sections were prepared for the observation of biofilms under a scanning electron microscope (Camscan MV 2300, Czech Republic) (Fig. 1).

Other roots were stored at $-25^{\circ} \mathrm{C}$ for $24 \mathrm{~h}$ to prevent or reduce generation of heat during the sampling phase. Dentin chips produced as a result of drilling the root canal walls with \#5 and \#6 Gates-Glidden drills were

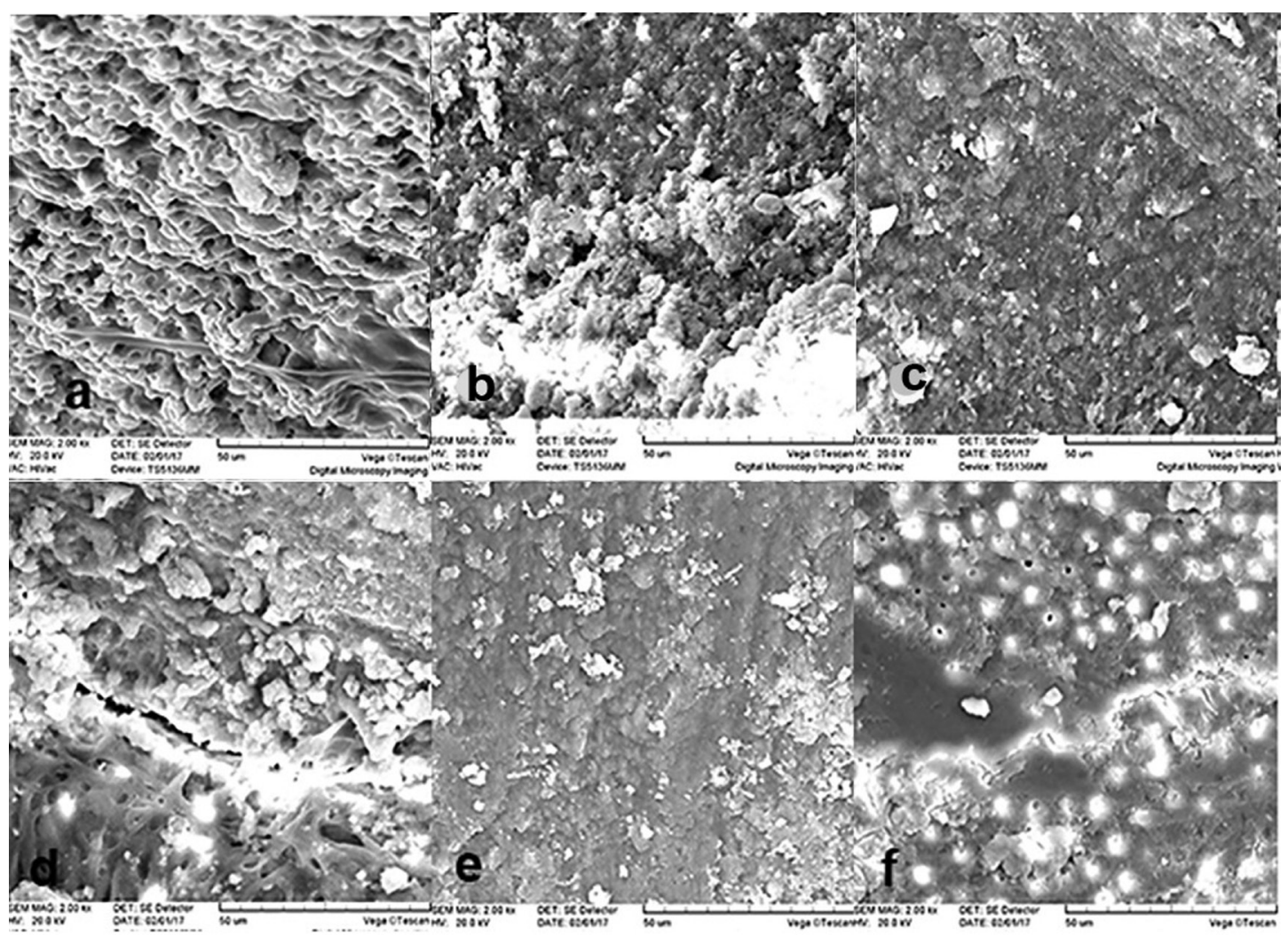

Fig. 1: a) Following normal saline (NS) irrigation, thick biofilm was still observed on the surface of the canal wall. b) After adding Direct curent (DC) to NS irrigation, the canal wall still contained a large number of bacteria. So the application of DC alone didn't have much effect on biofilm bacteria. c) Presence of high-frequency alternating current (AC) in NS irrigation killed much biofilm bacteria although it was a little but the reduction was significant compared with a and b. d) Following Chlorhexidine (CHX) irrigation, the number of surviving bacteria was reduced by application of CHX compared with NS. e) After adding Dc to CHX irrigation, the spread of the biofilm was evenly over the entire wall and a thin bacterial biofilm was remained on the surface of the canal wall. f) Presence of AC in CHX irrigation was completely effective in removing biofilm from the surface of the canal wall. 
collected in order to evaluate disinfection efficacy. The drills were placed in the root canals up to $1 \mathrm{~mm}$ short of the WL and approximately $10 \mu \mathrm{g}$ of dentin chips were collected from each root canal, which were carried into sterile tubes that contained $2 \mathrm{~mL}$ of normal saline solution, followed by vortexing for $20 \mathrm{sec}$. Serial one-tenth dilutions were prepared. Then $1 \mathrm{~mL}$ of each solution was added to 3 Muller-Hinton agar plates, followed by incubation at $37^{\circ} \mathrm{C}$ for $48 \mathrm{~h}$. All the procedures were carried out by observing aseptic conditions in a luminar flow chamber with sterile instruments. A classic colony counting procedure was applied to determine vital $E$. faecalis bacterial counts in Muller Hinton agar plates. After determining the colony-forming unit (CFU) in each root canal, the mean CFU of each group was determined ( $\mathrm{Ta}-$ ble 1).

-Statistical Analysis

Statistical analysis was performed with SPSS (Statistical Package for Social Science, SPSS, Version 20.0, SPSS, Chicago, IL, USA).
Table 2 presents the colony counts (CFUs) in six experimental groups for different irrigants and electric currents. Quantitative data were reported as means, medians, 95\% confidence interval, maximums and minimums.

Two-way ANOVA was used to compare the mean CFU values in groups of DC, AC and without current, regardless of the irrigants.

The results of Kolmogorov-Smirnov test showed normal distribution of data only in the normal saline solution group. One-way ANOVA was used for inter-group analysis in NS groups, and the HSD Tukey test was used for pair-wise comparisons; Kruskal-Wallis test was used for inter-group analysis in CHX groups; Mann-Whitney $\mathrm{U}$ test was used for pair-wise comparisons (Table 3 ). The level of significance was set at $P<0.05$.

\section{Results}

The results of two-way ANOVA showed that electric current significantly changed the CFU values $(P<0.001)$. According to pair-wise comparisons, there were signi-

Table 1: The distribution of groups.

\begin{tabular}{|c|c|c|c|c|c|c|}
\hline \multirow{6}{*}{$\mathrm{CHX}(\mathrm{n}=60)$} & \multirow[t]{2}{*}{ None $(n=20)$} & \multirow[t]{2}{*}{$\begin{array}{c}\text { irrigation with } \\
1 \mathrm{ml} \text { of CHX } 2 \% \\
\text { solution for } 5 \mathrm{~min}\end{array}$} & \multirow[t]{2}{*}{$\begin{array}{l}\text { irrigation with } 3 \\
\text { ml of sterile } \\
\text { normal saline }\end{array}$} & $\begin{array}{l}\text { Under observation of } \\
\text { scanning electron } \\
\text { microscope }(n=4)\end{array}$ & \multicolumn{2}{|c|}{ SEM observation } \\
\hline & & & & $\begin{array}{l}\text { sampling with Gates- } \\
\text { Glidden drills }(\mathrm{n}=16)\end{array}$ & & $\mathrm{CFU}$ \\
\hline & \multirow[t]{2}{*}{$\mathrm{DC}(\mathrm{n}=20)$} & \multirow{2}{*}{$\begin{array}{l}\text { irrigation with } 1 \\
\mathrm{ml} \text { of CHX } 2 \% \\
\text { solution \& apply- } \\
\text { ing DC for } 5 \text { min }\end{array}$} & \multirow[t]{2}{*}{$\begin{array}{l}\text { irrigation with } 3 \\
\text { ml of sterile } \\
\text { normal saline }\end{array}$} & $\begin{array}{l}\text { Under observation of } \\
\text { scanning electron } \\
\text { microscope }(n=4)\end{array}$ & SEM & observation \\
\hline & & & & $\begin{array}{l}\text { sampling with Gates- } \\
\text { Glidden drills }(\mathrm{n}=16)\end{array}$ & & $\mathrm{CFU}$ \\
\hline & \multirow[t]{2}{*}{$\mathrm{AC}(\mathrm{n}=20)$} & \multirow{2}{*}{$\begin{array}{l}\text { irrigation with } 1 \\
\text { ml of CHX } 2 \% \\
\text { solution \& apply- } \\
\text { ing AC for } 5 \text { min }\end{array}$} & \multirow[t]{2}{*}{$\begin{array}{l}\text { irrigation with } 3 \\
\text { ml of sterile } \\
\text { normal saline }\end{array}$} & $\begin{array}{l}\text { Under observation of } \\
\text { scanning electron } \\
\text { microscope }(n=4)\end{array}$ & SEM & observation \\
\hline & & & & $\begin{array}{l}\text { sampling with Gates- } \\
\text { Glidden drills }(\mathrm{n}=16)\end{array}$ & & $\mathrm{CFU}$ \\
\hline \multirow{6}{*}{ NS $(n=60)$} & \multirow[t]{2}{*}{ None $(\mathrm{n}=20)$} & \multirow[t]{2}{*}{$\begin{array}{l}\text { irrigation with } 1 \\
\mathrm{ml} \text { of NS solution } \\
\text { for } 5 \mathrm{~min}\end{array}$} & \multirow[t]{2}{*}{$\begin{array}{l}\text { irrigation with } 3 \\
\text { ml of sterile } \\
\text { normal saline }\end{array}$} & $\begin{array}{l}\text { Under observation of } \\
\text { scanning electron } \\
\text { microscope }(n=4)\end{array}$ & SEM & observation \\
\hline & & & & $\begin{array}{l}\text { sampling with Gates- } \\
\text { Glidden drills }(\mathrm{n}=16)\end{array}$ & & $\mathrm{CFU}$ \\
\hline & \multirow[t]{2}{*}{$\mathrm{DC}(\mathrm{n}=20)$} & \multirow{2}{*}{$\begin{array}{l}\text { irrigation with } 1 \\
\mathrm{ml} \text { of NS solution } \\
\& \text { applying DC for } \\
5 \mathrm{~min}\end{array}$} & \multirow[t]{2}{*}{$\begin{array}{l}\text { irrigation with } 3 \\
\text { ml of sterile } \\
\text { normal saline }\end{array}$} & $\begin{array}{l}\text { Under observation of } \\
\text { scanning electron } \\
\text { microscope }(n=4)\end{array}$ & SEM & observation \\
\hline & & & & $\begin{array}{l}\text { sampling with Gates- } \\
\text { Glidden drills }(n=16)\end{array}$ & & $\mathrm{CFU}$ \\
\hline & \multirow[t]{2}{*}{$\mathrm{AC}(\mathrm{n}=20)$} & \multirow{2}{*}{$\begin{array}{l}\text { irrigation with } 1 \\
\text { ml of NS solution } \\
\& \text { applying DC for } \\
5 \text { min }\end{array}$} & \multirow[t]{2}{*}{$\begin{array}{l}\text { irrigation with } 3 \\
\text { ml of sterile } \\
\text { normal saline }\end{array}$} & $\begin{array}{l}\text { Under observation of } \\
\text { scanning electron } \\
\text { microscope }(n=4)\end{array}$ & SEM & observation \\
\hline & & & & $\begin{array}{l}\text { sampling with Gates- } \\
\text { Glidden drills }(\mathrm{n}=16)\end{array}$ & & $\mathrm{CFU}$ \\
\hline
\end{tabular}


Table 2: The CFUs in 6 study groups.

\begin{tabular}{|c|c|c|c|c|}
\hline Groups & Mean (SD) & Median & Min & Max \\
\hline $\mathbf{2 \%}$ CHX & $119(117)$ & 80 & 10 & 480 \\
\hline NS+DC & $299533(150892)$ & 284000 & 78000 & 644000 \\
\hline NS+AC & $46280(16702)$ & 45200 & 8400 & 66200 \\
\hline $\mathbf{2 \%}$ CHX+DC & $50(32)$ & 50 & 10 & 130 \\
\hline $\mathbf{2 \%}$ CHX+AC & $0(0)$ & 0 & 0 & 0 \\
\hline NS (Control) & $332133(211098)$ & 312000 & 60000 & 822000 \\
\hline
\end{tabular}

Table 3: Pair-wise comparisons of the CFUs.

\begin{tabular}{|c|c|c|c|}
\hline Electric Groups & $\begin{array}{c}\text { HSD Tukey } \\
\boldsymbol{P} \text {-Value } \\
\text { (regardless of the irrigations) }\end{array}$ & $\begin{array}{c}\text { HSD Tukey } \\
\boldsymbol{P} \text {-Value } \\
\text { (NS groups) }\end{array}$ & $\begin{array}{c}\text { Mann-Whitney U } \\
\boldsymbol{P} \text {-value } \\
\text { (CHX groups) }\end{array}$ \\
\hline None DC & .823 & .824 & $0.000^{*}$ \\
\hline None AC & $.000^{*}$ & $.000^{*}$ & $0.043^{*}$ \\
\hline DC AC & $.000^{*}$ & $.000^{*}$ & $0.000^{*}$ \\
\hline
\end{tabular}

ficant differences between the AC and DC groups and also the $\mathrm{AC}$ group and the group without electric current $(P<0.001)$, but the difference between the DC group and the group without electric current was not significant $(P=0.823)$. The highest CFU difference was observed between the AC group and the group without electric current, with 142986.33 units higher in the group without current. Also in the NS groups, according to pair-wise comparisons, there were significant differences between the $\mathrm{AC}$ and $\mathrm{DC}$ groups and also between the $\mathrm{AC}$ group and the group without electric current $(P<0.001)$, but the difference between the DC group and the group without electric current was not significant $(P=0.824)$. In addition, in CHX groups, according to pair-wise comparisons, there were significant differences between the AC and $\mathrm{DC}$ groups and the $\mathrm{AC}$ group and the group without electric current and also between the DC group and the group without electric current.

\section{Discussion}

This study evaluated the effect of electric currents on antibacterial efficacy of chlorhexidine as a root canal irrigant against $E$. faecalis biofilm. The rationale for the selection of E. faecalis in the present study was that it is one of the most resistant intracanal bacteria and also it could create extra- and intra-radicular biofilms which are very difficult to eliminate from the infected root canals (10-12).

Electric currents improve the efficiency of biocides and antibiotics in destroying bacterial biofilms (21), and it has been suggested that electric currents could be considered as a safe and inexpensive method to increase the entrance of different therapeutic agents into the cells (27). In addition, electrostatic forces between bacterial species and surfaces are usually repulsive because virtually all the biomaterials are negatively charged similar to bacteria. It has been suggested electric currents might enhance such forces, resulting in the detachment of bacterial biofilms from the surface (17-20). In this study, two types of electric currents, including direct and alternating with high frequency applied by an electronic apex locator, were used. The results showed that the electric current, irrespective of the type of the irrigation agent, resulted in a decrease in bacterial colony counts. Consistent with our results, Liu et al. (19), Del Pozo et al. (18), and Stoodley et al. (28) concluded that corrosion occurred in metal electrodes used for evaluation of the effect of electric currents on the bacteria and the effect of the antibacterial activity of electric currents. Furthermore, it has been suggested that products of electrolysis increase the bactericidal efficiency of electric currents by increasing the amount of ions on the surface or within bacterial cells.

Moreover, the results of this study showed that the effect of direct current was significantly different between the groups in terms of the type of the irrigation agent. The use of DC in the $2 \%$ CHX group resulted in a decrease in bacterial colonies, which was significantly more than that in the $2 \% \mathrm{CHX}$ group without electric current. Although, the effect of direct current in the normal saline group as a canal irrigant reduced the colony counts, there was no significant difference from the normal saline group without electric current. Several ex vivo studies have reported similar results on the use of electric DC 
$(4,13,14)$ and declared that bioelectric effect could eradicate different gram-positive and gram-negative species and fungi (6).

Furthermore, consistent with the results of this study, Wellman et al. (17) confirmed that electric current alone had no or minimal effect on bacterial biofilm so strilant plus electric currents were necessary to achieve the optimum level. Furthermore, Wellman et al. (17) showed that there was a dose-dependent response in combining electric currents with antibiotics. Moreover, Jass et al. (14) concluded that electric currents could only improve the activity of some antibiotics. Therefore, the type of the material applied with electric current is important in decreasing bacterial counts. CHX has antibacterial effects without solubility effect; however, its application in association with electric current with low intensity (DC) could reduce the colony counts more than CHX alone. Therefore, application of electric currents increases its bioelectric effect and might cause solubility effect but have a minimal effect with normal saline. In addition, the results of the present study showed that the type of the material was effective up to $55 \%$ in decreasing bacterial counts.

In addition, the results of this study showed that the effect of alternating current (22) applied by an electronic apex locator in the normal saline group, and in particular in the CHX group resulted in the highest decrease in bacterial counts, which might be attributed to the higher electric current intensity in the electronic apex locator in comparison to the direct current. Also Stoodley et al. (28) showed that structural changes of biofilms, referred to as electrostatic influence, could occur due to the interaction between groups with charge in biofilm, $\mathrm{pH}$ effect and wire (electrode) charge, declaring that expansion and shrinkage of bacterial biofilm on the electrode surface occurred due to current polarity reversal.

However, in the present study, $\mathrm{pH}$ changes around the electrods and biofilm and the rate of structeral changes during the application of electric current were not mesured and further studies are necessary to evaluate $\mathrm{pH}$ changes on bacterial biofilms. Moreovere, further studies are recommended to evaluate the effect of electric currents with different intensities and on various bacterial species. However, the exact mechanism of the antibiofilm activity of DC and AC is unclear, necessitating further investigations.

\section{Conclusions}

According to the results of this study, application of electric current irrespective of type of canal irrigant could be effective in decreasing bacterial counts. The highest bioelectric effect was demonstrated when high-frequency alternating electric current was applied by an electronic apex locator with $\mathrm{CHX}$ as a canal irrigant.

\section{References}

1. Gomes B, Lilley J, Drucker D. Variations in the susceptibilities of components of the endodontic microflora to biomechanical procedures. International endodontic journal. 1996;29:235-41.

2. Peciuliene V, Balciuniene I, Eriksen HM, Haapasalo M. Isolation of Enterococcus faecalis in previously root-filled canals in a Lithuanian population. Journal of Endodontics. 2000;26:593-5.

3. Blenkinsopp SA, Khoury AE, Costerton JW. Electrical enhancement of biocide efficacy against Pseudomonas aeruginosa biofilms. Applied and environmental microbiology. 1992;58:3770-3.

4. Cao H, Jiang B, Li X, Yu G, Zhang Y, Zhong F. Influence of external electric current on the spatial distributions of porosity and fractional dimension of biofilms. Huan jing ke xue= Huanjing kexue/[bian ji, Zhongguo ke xue yuan huan jing ke xue wei yuan hui" Huan jing ke xue" bian ji wei yuan hui]. 2003;24:85-8.

5. Caubet R, Pedarros-Caubet F, Chu M, Freye E, de Belem Rodrigues $\mathrm{M}$, Moreau J, et al. A radio frequency electric current enhances antibiotic efficacy against bacterial biofilms. Antimicrobial agents and chemotherapy. 2004;48:4662-4.

6. Costerton JW, Ellis B, Lam K, Johnson F, Khoury AE. Mechanism of electrical enhancement of efficacy of antibiotics in killing biofilm bacteria. Antimicrobial agents and chemotherapy. 1994;38:2803-9.

7. Khoury AE, Lam K, Ellis B, Costerton JW. Prevention and control of bacterial infections associated with medical devices. ASAIO journal. 1992;38:M174-M8.

8. Larsen T, Fiehn N. Dental biofilm infections-an update. APMIS: acta pathologica, microbiologica, et immunologica Scandinavica. 2017; $125: 376$.

9. Mah TFC, O'Toole GA. Mechanisms of biofilm resistance to antimicrobial agents. Trends in microbiology. 2001;9:34-9.

10. Gajan EB, Aghazadeh M, Abashov R, Milani AS, Moosavi Z. Microbial flora of root canals of pulpally-infected teeth: Enterococcus faecalis a prevalent species. Journal of dental research, dental clinics, dental prospects. 2009;3:24.

11. Zand V, Milani AS, Amini M, Barhaghi MHS, Lotfi M, Rikhtegaran S, et al. Antimicrobial efficacy of photodynamic therapy and sodium hypochlorite on monoculture biofilms of Enterococcus faecalis at different stages of development. Photomedicine and laser surgery. 2014;32:245-51.

12. Zand V, Salem-Milani A, Shahi S, Akhi MT, Vazifekhah S. Efficacy of different concentrations of sodium hypochlorite and chlorhexidine in disinfection of contaminated Resilon cones. Medicina oral, patologia oral y cirugia bucal. 2012;17:e352.

13. Jass J, Costerton J, Lappin-Scott H. The effect of electrical currents and tobramycin on Pseudomonas aeruginosa biofilms. Journal of industrial microbiology. 1995;15:234.

14. Jass J, Lappin-Scott H. The efficacy of antibiotics enhanced by electrical currents against Pseudomonas aeruginosa biofilms. The Journal of antimicrobial chemotherapy. 1996;38:987.

15. McLeod B, Fortun S, Costerton J, Stewart P. Enhanced bacterial biofilm control using electromagnetic fields in combination with antibiotics. Methods in enzymology. 1999;310:656.

16. Stewart PS, Wattanakaroon W, Goodrum L, Fortun SM, McLeod BR. Electrolytic Generation of Oxygen Partially Explains Electrical Enhancement of Tobramycin Efficacy against Pseudomonas aeruginosa Biofilm. Antimicrobial Agents and Chemotherapy. 1999;43:292. 17. Wellman N, Fortun S, McLeod B. Bacterial biofilms and the bioelectric effect. Antimicrobial Agents and Chemotherapy. 1996;40:2012.

18. del Pozo JL, Rouse MS, Mandrekar JN, Steckelberg JM, Patel R. The Electricidal Effect: Reduction of Staphylococcus and Pseudomonas Biofilms by Prolonged Exposure to Low-Intensity Electrical $\mathrm{Cu}-$ rrent. Antimicrobial Agents and Chemotherapy. 2009;53:41.

19. Liu W, Brown M, Elliott T. Mechanisms of the bactericidal activity of low amperage electric current (DC). The Journal of antimicrobial chemotherapy. 1997;39:687.

20. Matsunaga T, Nakasono S, Masuda S. Electrochemical sterilization of bacteria absorbed on granular activated carbon. FEMS microbiology letters. 1992;72:255.

21. Poortinga A, Bos R, Busscher H. Controlled electrophoretic depo- 
sition of bacteria to surfaces for the design of biofilms. Biotechnology and bioengineering. 2000;67:117.

22. Arias-Moliz M, Ferrer-Luque C, González-Rodríguez M, Valderrama M, Baca P. Eradication of Enterococcus faecalis biofilms by cetrimide and chlorhexidine. Journal of endodontics. 2010;36:87.

23. Haapasalo H, Sirén E, Waltimo T, Ørstavik D, Haapasalo M. Inactivation of local root canal medicaments by dentine: an in vitro study. International endodontic journal. 2000;33:126.

24. Portenier I, Haapasalo H, Rye A, Waltimo T, Ørstavik D, Haapasalo M. Inactivation of root canal medicaments by dentine, hydroxylapatite and bovine serum albumin. International endodontic journal. 2001;34:184.

25. Grundling GL, Zechin JG, Jardim WM, de Oliveira SD, de Figueiredo JA. Effect of ultrasonics on Enterococcus faecalis biofilm in a bovine tooth model. J Endod. 2011;37:1128-33.

26. Liu H, Wei X, Ling J, Wang W, Huang X. Biofilm formation capability of Enterococcus faecalis cells in starvation phase and its susceptibility to sodium hypochlorite. Journal of endodontics. 2010;36:630. 27. Thomasset A, Lenoir J, Roullet C, Wilmore D. A weak electrical current enhances intracellular delivery of therapeutic substances. Medical hypotheses. 2000;55:326.

28. Stoodley P, Yang S, Lappin-Scott H, Lewandowski Z. Relationship between mass transfer coefficient and liquid flow velocity in heterogenous biofilms using microelectrodes and confocal microscopy. Biotechnology and bioengineering. 1997;56:681.

\section{Conflicts of Interest}

The authors declare that they have no conflict of interest. 